- Original Article

\title{
Time to First Cigarette and Hypertension in Korean Male Smokers
}

\author{
Saerom Lee, Miae Jang, Hye-Mi Noh, Hye-Young Oh, Hong Ji Song, Kyung Hee Park, Yu-Jin Paek* \\ Department of Family Medicine, Hallym University Sacred Heart Hospital, Hallym University College of Medicine, Anyang, Korea
}

Background: Morning blood pressure surge affects to cardiovascular disease risk. Short time to first cigarette (TTFC) after waking can enhance morning blood pressure surge, and accelerate atherosclerosis.

Methods: We investigated that the relationship between TTFC and blood pressure. The study subjects included male current smokers $(\mathrm{n}=211)$ who had health check-up in Hallym University Sacred Heart Hospital from July to September, 2014. We categorized the subjects into 2 groups according to TTFC; early TTFC (TTFC $<30$ minutes) and late TTFC (TTFC $\geq 30$ minutes), and the subjects who were taking antihypertensive medications or had a high blood pressure ( $>140 \mathrm{~mm} \mathrm{Hg}$ or $90 \mathrm{~mm} \mathrm{Hg}$ ) were defined as hypertensive group. Multivariate logistic regression was performed to estimate the odds ratio and $95 \%$ confidence interval to investigate the association between TTFC and hypertensive group.

Results: Compared with late TTFC, early TTFC had higher odds (odds ratio [OR], 3.87; 95\% confidence interval [CI], 1.89-7.94) for hypertensive group. After adjusting confounding factors, early TTFC was significantly associated with an increased risk of hypertension ( $\mathrm{OR}, 4.43 ; 95 \% \mathrm{CI}, 1.84-10.70)$.

Conclusion: early TTFC after waking is associated with hypertension. It suggests delaying TTFC might help to control of blood pressure among the current smokers who are not ready to immediately quit smoking.

Keywords: Smoking; Hypertension; Cardiovascular Disease; Metabolic Syndrome X 


\section{INTRODUCTION}

Hypertension is a major risk factor for cardiovascular disease (CVD) and stroke. ${ }^{1)}$ Circadian blood pressure (BP) variants, especially morning BP surge, are associated with CVD risk and stroke. ${ }^{2-4)}$ Cigarette smoking is a major risk factor for atherosclerosis, stroke, coronary heart disease, and occlusive peripheral vascular disease. ${ }^{5,6)}$ In particular, nicotine affects BP and heart rate changes; ${ }^{7-9)}$ there are dose-response relationships between the number of cigarettes and both serum nicotine levels and CVD risk. ${ }^{10,11)}$ Nicotine and other substances absorbed as a result of cigarette smoking can increase BP by about 10 to $15 \mathrm{~mm} \mathrm{Hg}$ for about 30 minutes. ${ }^{12-16)} \mathrm{BP}$ is usually elevated upon waking, ${ }^{8,9)}$ and a short time to first cigarette (TTFC) after waking can induce a morning BP surge. Therefore, individuals who smoke a cigarette as soon as they wake up may experience rapid BP changes that result in blood vessel injury and accelerated atherosclerosis. ${ }^{2,3,9,17,18)}$ TTFC was recently reported to be associated with cancers of the lung, upper airway, and pancreas. ${ }^{19,20)}$ Accordingly, smoking is a known cancer-causing behavior and vascular disease risk factor. Moreover, most metabolic risk factors affect CVD and cerebrovascular disease. Although several epidemiologic studies indicate the BP of smokers is similar to or lower than that of nonsmokers, one study reported significantly higher systolic BP in smokers than in nonsmokers. ${ }^{13)} \mathrm{BP}$ also differs between heavy and light smokers. Thus, TTFC may also be associated with hypertension.

Besides smoking itself, nicotine dependence may be associated with increased CVD risk, especially hypertension. As TTFC can be used as a measure of nicotine dependence, it may be associated with high BP and increased risk of CVD and stroke. Accordingly, BP changes may be greater with earlier TTFCs. Because the relationship between TTFC and hypertension risk remains unclear, this study evaluated this relationship in male Korean smokers.

\section{METHODS}

\section{Subjects}

This study included 211 men who visited the Comprehensive Medical Examination Center of Hallym University Sacred Heart Hospital from July to September 2014. Only current male smokers were included, because few female smokers presented to our center. We excluded subjects with suspected angina, stroke, or secondary hypertension, as well as those in the acute stage of infectious disease. Participants provided informed consent to participate in this study when collecting information. All study protocols were approved by the Hallym University Sacred Heart Hospital institutional review board (IRB No. 2008-I013).

\section{Blood Pressure}

The subjects were allowed to sit for 10 minutes, after which time BP was measured using the DINAMAP DPC100X-EN automated BP monitor (GE Medical System Information Technologies, Milwaukee, WI, USA). Morning BP was assessed in the complex healthcare center room. Patients with hypertension who took antihypertensive medications were required to take them before BP measurement. If the automatically measured BP was beyond the normal range, a trained nurse measured BP manually using a mercury sphygmomanometer, and the manually measured BP level was used for analysis. Hypertension was defined in subjects taking antihypertensive medications and in those whose systolic or diastolic BP exceeded 140 or $90 \mathrm{~mm} \mathrm{Hg}$, respectively.

\section{Clinical Variables}

We collected information regarding cigarette smoking history, TTFC, physical activity, and alcohol consumption using a structured questionnaire and the Beck Depression Inventory. We also collected family and personal medical histories of hypertension, diabetes, and dyslipidemia.

TTFC data were collected by physicians and by using a structured questionnaire. TTFC was categorized as $\geq 60,31-60,6-30$, or $\leq 5$ minutes. Subjects were then divided into the early $(<30$ minutes) and late ( $\geq 30$ minutes) TTFC groups. Participants who consumed $>14$ alcoholic drinks per week were classified as 'problem drinkers' according to National Institute of Alcohol Abuse and Alcoholism criteria. Height, weight, and circumferences of the waist, hip, and abdomen were measured. Weight and height were measured by trained nurses using calibrated equipment. Body mass index (BMI) was calculated as weight $(\mathrm{kg}) /$ height $(\mathrm{cm})^{2}$. Waist circumference was measured to the nearest $0.1 \mathrm{~cm}$ during exhalation using a measuring tape at the horizontal plane midway between the inferior costal margin and iliac crest at the midaxillary line.

\section{Laboratory Analysis}

Blood samples were obtained for routine blood chemistry tests. Samples were collected from the brachial vein after the subjects had fasted for at least 8 hours. The white blood cell count and hemoglobin, glucose, hemoglobin Alc (HbAlc), total cholesterol, high density lipoprotein (HDL) cholesterol, triglyceride (TG), low density lipoprotein (LDL), high-sensitivity C-reactive protein (hs-CRP), serum creatinine, aspartate transaminase, alanine transaminase, and gamma-glutamyltransferase (GGT) levels were analyzed.

\section{Statistical Analysis}

All data were analyzed using IBM SPSS ver. 22.0 (IBM Co., Armonk, NY, USA). Continuous and categorical variables were tested for normality using the Kolmogorov-Smirnov test. An 
independent sample t-test was used to analyze continuous variables. Categorical variables were analyzed by the $\chi^{2}$ test. Serum TG, HDL, and hs-CRP were log-transformed before statistical analysis because their distributions were skewed. Univariate and multivariate analyses were performed by binary logistic regression. To avoid multicollinearity, we divided subjects into diabetes and dyslipidemia groups. Diabetes was defined as the use of diabetes medication, fasting glucose $\geq 126 \mathrm{mg} / \mathrm{dL}$, or HbAlc $\geq 6.5 \%$. Dyslipidemia was defined as the use of dyslipidemia medication, $\mathrm{TG} \geq 150 \mathrm{mg} / \mathrm{dL}, \mathrm{HDL}<40 \mathrm{mg} / \mathrm{dL}$, or LDL $\geq 130 \mathrm{mg} / \mathrm{dL}$. Most parameters significant at $\mathrm{P}<0.05$ in the bivariate model were entered into the multivariate model. We also adjusted the multivariate model for the variables that were not significant but are important risk factors for hypertension, including BMI, smoking history, dyslipidemia, and problem drinking.

All tests were 2 sided, and the level of significance was set at $\mathrm{P}<0.05$. There were no missing values in this analysis.

\section{RESULTS}

The baseline characteristics of the subjects are shown in Table 1. Subjects were divided into hypertension and nonhypertension groups. Significant differences were found in systolic and

Table 1. Comparison of baseline characteristics between the hypertension and nonhypertension groups

\begin{tabular}{|c|c|c|c|}
\hline Variable & Nonhypertension group $(n=161)$ & Hypertension group $(n=50)$ & P-value \\
\hline Age (y) & $43.8 \pm 7.4$ & $48.4 \pm 7.2$ & $<0.001$ \\
\hline Height (cm) & $172.1 \pm 6.4$ & $172.3 \pm 6.9$ & 0.836 \\
\hline Weight $(\mathrm{kg})$ & $71.8 \pm 9.6$ & $74.5 \pm 10.6$ & 0.085 \\
\hline Body mass index $\left(\mathrm{kg} / \mathrm{cm}^{2}\right)$ & $24.2 \pm 2.8$ & $25.0 \pm 2.9$ & 0.067 \\
\hline $\mathrm{TTFC}^{*}<30 \mathrm{~min}$ & $71(44.1)$ & $37(74.0)$ & $<0.001$ \\
\hline $\begin{array}{l}\text { No. of cigarettes per day } \\
0-10 \\
11-20 \\
>20\end{array}$ & $\begin{array}{l}19(12.0) \\
72(45.6) \\
67(42.4)\end{array}$ & $\begin{array}{c}4(8.0) \\
23(46.0) \\
23(46.0)\end{array}$ & 0.829 \\
\hline $\begin{array}{l}\text { Years of smoking } \\
\quad<10 \\
10-20 \\
20-30 \\
>30\end{array}$ & $\begin{array}{c}7(4.5) \\
39(24.5) \\
78(49.1) \\
35(22.0)\end{array}$ & $\begin{aligned} 1 & (2.0) \\
6 & (12.2) \\
28 & (57.1) \\
14 & (28.6)\end{aligned}$ & 0.336 \\
\hline $\begin{array}{l}\text { Problem drinking }{ }^{\dagger} \\
\text { Physical activity }^{\ddagger} \\
\text { Blood pressure }^{\S} \\
\text { Systolic blood pressure }(\mathrm{mm} \mathrm{Hg}) \\
\text { Diastolic blood pressure }(\mathrm{mm} \mathrm{Hg})\end{array}$ & $\begin{aligned} 63(39.6) \\
15(9.7) \\
118.0 \pm 10.0 \\
75.8 \pm 7.1\end{aligned}$ & $\begin{aligned} 24 & (51.1) \\
6 & (12.8) \\
133.1 & \pm 14.3 \\
86.8 & \pm 9.6\end{aligned}$ & $\begin{array}{r}0.181 \\
0.588 \\
<0.001 \\
<0.001\end{array}$ \\
\hline $\begin{array}{l}\text { Lipid profile } \\
\text { HDL (mg/dL) } \\
\text { Log-HDL } \\
\text { LDL (mg/dL) } \\
\text { Triglycerides (mg/dL) } \\
\text { Log-triglycerides }\end{array}$ & $\begin{array}{c}54.1 \pm 14.4 \\
4.0 \pm 0.3 \\
125.1 \pm 32.9 \\
139.5 \pm 84.1 \\
4.8 \pm 0.5\end{array}$ & $\begin{array}{c}50.7 \pm 14.5 \\
3.9 \pm 0.3 \\
116.8 \pm 35.4 \\
185.8 \pm 128.1 \\
5.0 \pm 0.6\end{array}$ & $\begin{array}{l}0.153 \\
0.107 \\
0.128 \\
0.019 \\
0.007\end{array}$ \\
\hline Fasting blood glucose & $90.5 \pm 13.5$ & $106.5 \pm 37.5$ & 0.004 \\
\hline $\mathrm{HbA1c}(\%)$ & $5.4 \pm 0.5$ & $6.1 \pm 1.3$ & $<0.001$ \\
\hline High-sensitivity C-reactive protein (mg/dL) & $1.1 \pm 1.4$ & $1.6 \pm 1.9$ & 0.071 \\
\hline Creatinine $(\mathrm{mg} / \mathrm{dL})$ & $0.9 \pm 0.1$ & $0.9 \pm 0.1$ & 0.687 \\
\hline Aspartate transaminase (mg/dL) & $23.6 \pm 8.0$ & $28.3 \pm 17.4$ & 0.064 \\
\hline Alanine transaminase $(\mathrm{mg} / \mathrm{dL})$ & $25.3 \pm 15.8$ & $30.8 \pm 25.1$ & 0.148 \\
\hline Gamma-glutamyltransferase (mg/dL) & $42.5 \pm 33.2$ & $68.1 \pm 66.0$ & 0.011 \\
\hline Beck Depression Inventory Score & $5.6 \pm 4.8$ & $5.7 \pm 5.1$ & 0.374 \\
\hline Use of diabetes medications & $3(1.9)$ & $8(16.0)$ & $<0.001$ \\
\hline Use of hypertension medications & 0 & $22(44.0)$ & $<0.001$ \\
\hline Use of dyslipidemia medications & $3(1.9)$ & $6(12.0)$ & 0.006 \\
\hline Diabetes" & $30(19.4)$ & $22(45.8)$ & $<0.001$ \\
\hline Dyslipidemia? & $151(93.8)$ & $44(89.8)$ & 0.349 \\
\hline Metabolic syndrome & $13(8.1)$ & $15(30.6)$ & $<0.001$ \\
\hline
\end{tabular}

Values are presented as mean \pm standard deviation or number (\%). P-values were calculated using t-tests or the $\chi^{2}$ tests. HDL, high density lipoprotein; LDL, low density lipoprotein; HbA1c, hemoglobin A1c.

${ }^{*}$ Time to first cigarette after waking up in the morning. ${ }^{\dagger}$ Frequency/wk $\times$ mean amount per glass $\geq 14$. ${ }^{\ddagger}>3$ times per week and $>1$ hour per session. ${ }^{\S}$ Systolic or diastolic blood pressure $\geq 140$ or $\geq 90 \mathrm{~mm} \mathrm{Hg}$, respectively or use of antihypertensive medications. "Use of diabetes medication, fasting glucose $\geq 126 \mathrm{mg} / \mathrm{dL}$, or $\mathrm{HbA} 1 \mathrm{c} \geq 6.5 \%$. "Use of dyslipidemia medications, triglycerides $\geq 150 \mathrm{mg} / \mathrm{dL}, \mathrm{HDL}<40 \mathrm{mg} / \mathrm{dL}$, or LDL $\geq 130 \mathrm{mg} / \mathrm{dL}$. 
Table 2. Univariate logistic regression analysis of factors associated with hypertension

\begin{tabular}{|c|c|c|c|}
\hline Variable & Odds ratio & $\begin{array}{l}95 \% \text { confidence } \\
\text { interval }\end{array}$ & P-value \\
\hline Age & 1.09 & $1.04-1.14$ & $<0.001$ \\
\hline TTFC $\geq 30 \mathrm{~min}$ & 1.00 (reference) & & \\
\hline TTFC $<30 \mathrm{~min}$ & 3.87 & $1.89-7.94$ & $<0.001$ \\
\hline \multicolumn{4}{|l|}{ Smoking } \\
\hline \multicolumn{4}{|l|}{ Cigarettes per day } \\
\hline $0-10$ & 1.00 (reference) & & 0.684 \\
\hline $11-20$ & 2.03 & $0.55-7.49$ & \\
\hline$>20$ & 2.15 & $0.58-7.95$ & \\
\hline \multicolumn{4}{|l|}{ Years of smoking } \\
\hline$<10$ & 1.00 (reference) & & 0.433 \\
\hline 10-20 & 1.11 & $0.12-10.65$ & \\
\hline 20-30 & 2.60 & $0.31-22.08$ & \\
\hline$>30$ & 2.88 & $0.32-25.65$ & \\
\hline \multicolumn{4}{|l|}{ Alcohol } \\
\hline Non-problem drinking & 1.00 (reference) & & \\
\hline Problem drinking* & 1.52 & $0.84-2.74$ & 0.165 \\
\hline \multicolumn{4}{|l|}{ Exercise } \\
\hline Exercise $^{\dagger}$ & 1.36 & $0.50-3.72$ & 0.554 \\
\hline Nonexercise & 1.00 (reference) & & \\
\hline Body mass index & 1.10 & $0.98-1.23$ & 0.069 \\
\hline \multicolumn{4}{|l|}{ Lipid } \\
\hline Triglycerides $<150$ mg/dL & 1.00 (reference) & & \\
\hline Triglyceride $\geq 150$ mg/dL & 2.31 & $1.21-4.41$ & 0.028 \\
\hline $\mathrm{HDL}>40 \mathrm{mg} / \mathrm{dL}$ & 1.00 (reference) & & \\
\hline $\mathrm{HDL} \leq 40 \mathrm{mg} / \mathrm{dL}$ & 1.41 & $0.75-2.65$ & 0.018 \\
\hline $\mathrm{LDL}<130 \mathrm{mg} / \mathrm{dL}$ & 1.00 (reference) & & \\
\hline $\mathrm{LDL} \geq 130 \mathrm{mg} / \mathrm{dL}$ & 0.87 & $0.45-1.66$ & 0.706 \\
\hline \multicolumn{4}{|l|}{$\mathrm{HbA1C}$} \\
\hline $\mathrm{HbA} 1 \mathrm{c}<6.5 \%$ & 1.00 (reference) & & \\
\hline $\mathrm{HbA} 1 \mathrm{c} \geq 6.5 \%$ & 5.76 & $2.20-15.10$ & $<0.001$ \\
\hline Fasting blood glucose & 1.03 & $1.02-1.05$ & $<0.001$ \\
\hline \multicolumn{4}{|l|}{ HsCRP } \\
\hline $\mathrm{HsCRP}<3.0 \mathrm{mg} / \mathrm{dL}$ & 1.00 (reference) & & \\
\hline $\mathrm{HsCRP} \geq 3.0 \mathrm{mg} / \mathrm{dL}$ & 2.60 & $0.92-7.38$ & 0.095 \\
\hline Gamma-glutamyltransferase & 1.01 & $1.00-1.02$ & 0.002 \\
\hline Aspartate transaminase & 1.04 & $1.01-1.06$ & 0.005 \\
\hline Alanine transaminase & 1.01 & $1.00-1.03$ & 0.062 \\
\hline Diabetes $^{\ddagger}$ & 3.53 & $1.76-7.01$ & $<0.001$ \\
\hline Dyslipidemia ${ }^{\S}$ & 0.58 & $0.19-1.80$ & 0.347 \\
\hline Metabolic syndrome & 4.65 & $2.18-9.92$ & $<0.001$ \\
\hline
\end{tabular}

Univariate analysis was performed by binary logistic regression.

TTFC, time to first cigarette after waking up in the morning; HDL, high density lipoprotein; LDL, low density lipoprotein; HDA1c, hemoglobin A1c; hsCRP, high-sensitivity C reactive protein; GGT, gamma-glutamyltransferase.

${ }^{*}$ Frequency/wk $\times$ mean amount per glass $\geq 14$. ${ }^{\dagger}$ Regular exercise: $>3$ times per

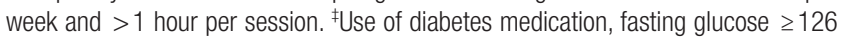
$\mathrm{mg} / \mathrm{dL}$, or $\mathrm{HbA} 1 \mathrm{c} \geq 6.5 \%$. . Use of dyslipidemia medications, triglycerides $\geq 150 \mathrm{mg} /$ $\mathrm{dL}, \mathrm{HDL}<40 \mathrm{mg} / \mathrm{dL}$, or $\mathrm{LDL} \geq 130 \mathrm{mg} / \mathrm{dL}$. diastolic BP, alcohol consumption frequency, smoking duration, HbAlc, GGT, and fasting blood glucose between the hypertension and nonhypertension groups $(\mathrm{P}<0.05)$.

Furthermore, significant differences were found between the hypertension and nonhypertension groups with respect to several risk factors for atherosclerosis. Early TTFC was associated with hypertension and was a risk factor for hypertension (odds ratio $[\mathrm{OR}], 3.87$; $95 \%$ confidence interval $[\mathrm{CI}], 1.89$ to 7.94 ) (Table 2). Other factors associated with metabolic syndrome, with the exception of HDL and LDL levels, were risk factors for hypertension. However, the number of cigarettes smoked daily, smoking duration, alcohol consumption, BMI, and physical inactivity were not significant risk factors for hypertension. The results of the multivariate logistic regression analysis adjusted for age, smoking history (years of smoking and number of cigarettes per day), BMI, physical activity, diabetes, dyslipidemia, and problem drinking are shown in Table 3. The age-adjusted OR (i.e., risk) in the hypertension group for early TTFC smokers was 3.60 ( $95 \% \mathrm{CI}, 1.74$ to 7.45 ). After adjusting for age, smoking history (years of smoking and number of cigarettes per day), BMI, physical activity, diabetes, and dyslipidemia, early TTFC was associated with an increased risk of hypertension (OR, 4.66; 95\% CI, 2.00 to 11.12). In the model adjusted for age, smoking history (number of cigarettes per day and years of smoking), BMI, physical activity, dyslipidemia, diabetes, and problem drinking, early TTFC was associated with an increased risk of hypertension (OR, 4.43; 95\% CI, 1.84 to 10.70). After adjustment, the OR for hypertension tended to increase with early TTFC in the hypertension group.

\section{DISCUSSION}

Several recent studies have investigated the association between TTFC and risk of cancer, especially lung and upper airway cancers. The dose-dependent relationships between TTFC and serum nicotine levels and the tobacco-specific carcinogen urinary 4-methylnitrosamino-1-3-pyridyl-1-butanol are well known. ${ }^{10,21)}$ The present study is the first to investigate the relationship between TTFC and hypertension (i.e., BP).

In this study, no significant differences were found in the number of smoking years or number of cigarettes per day be-

Table 3. Multiple logistic regression analysis of risk of hypertension group according to TTFC

\begin{tabular}{|c|c|c|c|c|c|c|c|c|c|c|}
\hline & \multicolumn{2}{|c|}{ Model 1} & \multicolumn{2}{|c|}{ Model 2} & \multicolumn{2}{|c|}{ Model 3} & \multicolumn{2}{|c|}{ Model 4} & \multicolumn{2}{|c|}{ Model 5} \\
\hline & $\mathrm{OR}$ & $95 \% \mathrm{Cl}$ & $\mathrm{OR}$ & $95 \% \mathrm{Cl}$ & $\mathrm{OR}$ & $95 \% \mathrm{Cl}$ & $\mathrm{OR}$ & $95 \% \mathrm{Cl}$ & $\mathrm{OR}$ & $95 \% \mathrm{Cl}$ \\
\hline TTFC $\geq 30 \mathrm{~min}$ & 1 & & 1 & & 1 & & 1 & & 1 & \\
\hline TTFC $<30 \mathrm{~min}$ & 3.60 & $1.74-7.45$ & 4.17 & $1.84-9.45$ & 4.38 & $1.89-10.13$ & 4.66 & $2.00-11.12$ & 4.43 & $1.84-10.70$ \\
\hline
\end{tabular}

Model 1: adjusted for age. Model 2: adjusted for age and smoking history (number of cigarettes per day and years of smoking). Model 3: adjusted for age, smoking history (number of cigarettes per day and years of smoking), BMl, and physical activity. Model 4: adjusted for age, smoking history (number of cigarettes per day and years of smoking), BMI, physical activity, dyslipidemia, and diabetes. Model 5: adjusted for age, smoking history (number of cigarettes per day and years of smoking), BMl, physical activity, dyslipidemia, diabetes, and problem drinking.

TTFC, time to first cigarette after waking up in the morning; OR, odds ratio; $\mathrm{Cl}$, confidence interval; BMl, body mass index. 
tween the hypertension and nonhypertension groups. This finding can be explained in two ways. First, early TTFC smokers tend to take more and larger puffs; therefore, early TTFC smokers are exposed to more nicotine than late TTFC smokers, even if they smoke the same number of cigarettes per day for the same number of years. ${ }^{22)}$ Second, the early TTFC smokers tend to have a slower nicotine metabolism, necessitating higher nicotine intake.

Hypertension is associated with arterial stiffness, and arterial stiffness is related to subclinical atherosclerosis. Someone who smokes cigarettes is exposed to not only nicotine but also other substances that contribute to atherosclerotic properties of the endothelium. Therefore, heavy smokers consume more nicotine and related substances. Inhalation of tobacco smoke may be related to an increased risk of hypertension. Elevations in serum nicotine levels lead to widespread augmentation of sympathetic nervous system activity. Activation of the sympathetic nervous system promotes vasoconstriction, which increases BP. BP levels exhibit a diurnal variation, decreasing during sleep and surging upon waking. Early TTFC smokers have a steeper BP surge upon waking, and this may accelerate the process of atherosclerosis. Our results suggest that TTFC is associated with hypertension as well as a higher uptake of nicotine and tobacco smoke for the above-mentioned reasons.

GGT, which is reported to be associated with the pathophysiologic process of atherosclerosis and oxidative stress, ${ }^{23)}$ was elevated in the early TTFC group. Therefore, higher GGT levels in the early TTFC group compared with the late TTFC group might indicate oxidative stress.

Lung cancer is also strongly associated with heavy smoking owing to the compensatory behavior of such smokers (e.g., deeply inhaling smoke)..$^{19,24,25)}$ Similarly, in the present study, the early TTFC group may have inhaled more deeply and rapidly to compensate for nicotine insufficiency in the morning immediately after waking, and this behavior may acutely affect the cardiovascular system. ${ }^{13,26)}$ Smokers have reduced CYP2A6 activity, resulting in slow nicotine metabolism. ${ }^{25)}$ Light smokers tend to have a slow nicotine metabolism. However, in the present study, no significant association was found between the number of cigarettes smoked or the number of smoking years and hypertension in the hypertension group. This suggests that TTFC may be independently associated with hypertension. High BP may induce the vascular remodeling (i.e., structural, mechanical, and functional changes) that occurs in patients with high BP may lead to atherosclerosis. ${ }^{27)}$

Morning hypertension and BP surge significantly increase the risk of cerebrovascular disease and CVD. ${ }^{2,3)}$ Although early TTFC may induce a morning BP surge, we were unable to identify such a relationship in the present study. BP increases about 10 to $15 \mathrm{~mm} \mathrm{Hg}$ when upon waking and about $30 \mathrm{~mm} \mathrm{Hg}$ if upon smoking immediately after waking. ${ }^{12-16)}$ However, there is cur- rently no standard definition of morning BP surge. In the JMSABPM (ambulatory BP monitoring) study, average increases of 55 and $37 \mathrm{~mm} \mathrm{Hg}$ were related to poor CVD outcomes. Large BP changes may also result in damage to the endothelium of vessels. ${ }^{3,28}$ Patients at high risk of vascular disease should be encouraged to stop smoking; if they are unable to quit, then they should be advised to delay smoking after waking.

The subjects in this study visited the healthcare center only once for a regular health check-up. Therefore, we were unable to determine 24-hour ambulatory BP or whether they had unknown 'white coat' hypertension or morning hypertension with a non-dipping pattern. Moreover, although hypertension is strongly associated with high salt intake, we did not inquire about salt consumption. Therefore, future studies should include more precise outcome measures using ambulatory BP monitoring and information regarding dietary salt intake.

In conclusion, TTFC after waking is associated with hypertension and may be associated with BP changes and atherosclerosis.

\section{CONFLICT OF INTEREST}

No potential conflict of interest relevant to this article was reported.

\section{ACKNOWLEDGMENTS}

Taekyun Lee, Geonhyeok Kim, and Hyoeun Lee who are residents of Hallym Sacred Heart Hospital asked to health examinee several questions about smoking.

\section{REFERENCES}

1. AlGhatrif M, Strait JB, Morrell CH, Canepa M, Wright J, Elango P, et al. Longitudinal trajectories of arterial stiffness and the role of blood pressure: the Baltimore Longitudinal Study of Aging. Hypertension 2013; 62:934-41.

2. Kario K. Morning surge in blood pressure and cardiovascular risk: evidence and perspectives. Hypertension 2010;56:765-73.

3. Kario K. Morning surge in blood pressure: a phenotype of systemic hemodynamic atherothrombotic syndrome. Am J Hypertens 2015;28:7-9.

4. Muller JE, Tofler GH, Stone PH. Circadian variation and triggers of onset of acute cardiovascular disease. Circulation 1989;79:733-43.

5. Benowitz NL. Cigarette smoking and cardiovascular disease: pathophysiology and implications for treatment. Prog Cardiovasc Dis 2003; 46:91-111.

6. Domino EF, Ni L, Xu Y, Koeppe RA, Guthrie S, Zubieta JK. Regional cerebral blood flow and plasma nicotine after smoking tobacco cigarettes. Prog Neuropsychopharmacol Biol Psychiatry 2004;28:319-27.

7. Benowitz NL. The role of nicotine in smoking-related cardiovascular disease. Prev Med 1997;26:412-7.

8. Benowitz NL, Gourlay SG. Cardiovascular toxicity of nicotine: implica- 
tions for nicotine replacement therapy. J Am Coll Cardiol 1997;29:142231.

9. Benowitz NL, Porchet H, Sheiner L, Jacob P 3rd. Nicotine absorption and cardiovascular effects with smokeless tobacco use: comparison with cigarettes and nicotine gum. Clin Pharmacol Ther 1988;44:23-8.

10. Branstetter SA, Muscat JE. Time to first cigarette and serum cotinine levels in adolescent smokers: National Health and Nutrition Examination Survey, 2007-2010. Nicotine Tob Res 2013;15:701-7.

11. Muscat JE, Stellman SD, Caraballo RS, Richie JP Jr. Time to first cigarette after waking predicts cotinine levels. Cancer Epidemiol Biomarkers Prev 2009;18:3415-20.

12. Head GA, Andrianopoulos N, McGrath BP, Martin CA, Carrington MJ, Lukoshkova EV, et al. Predictors of mean arterial pressure morning rate of rise and power function in subjects undergoing ambulatory blood pressure recording. PLoS One 2014;9:e93186.

13. Moolchan ET, Hudson DL, Schroeder JR, Sehnert SS. Heart rate and blood pressure responses to tobacco smoking among African-American adolescents. J Natl Med Assoc 2004;96:767-71.

14. Niaura R, Shadel WG, Goldstein MG, Hutchinson KE, Abrams DB. Individual differences in responses to the first cigarette following overnight abstinence in regular smokers. Nicotine Tob Res 2001;3:37-44.

15. Primatesta P, Falaschetti E, Gupta S, Marmot MG, Poulter NR. Association between smoking and blood pressure: evidence from the health survey for England. Hypertension 2001;37:187-93.

16. Terborg C, Bramer S, Weiller C, Rother J. Short-term effect of cigarette smoking on $\mathrm{CO}(2)$-induced vasomotor reactivity in man: a study with near-infrared spectroscopy and tanscranial Doppler sonography. J Neurol Sci 2002;205:15-20.

17. Kikuya M, Hozawa A, Ohokubo T, Tsuji I, Michimata M, Matsubara M, et al. Prognostic significance of blood pressure and heart rate variabilities: the Ohasama study. Hypertension 2000;36:901-6.

18. Kim HJ, Kim KH, Kil HR. Correlation between the morning hypertension on ambulatory blood pressure monitoring and the left ventricular mass in children. Korean J Pediatr 2014;57:403-9.
19. Gu F, Wacholder S, KovalchikS, Panagiotou OA, Reyes-Guzman C, Freedman ND, et al. Time to smoke first morning cigarette and lung cancer in a case-control study. J Natl Cancer Inst 2014;106:dju118.

20. Matsuo K, Gallus S, Negri E, Kawakita D, Oze I, Hosono S, et al. Time to first cigarette and upper aerodigestive tract cancer risk in Japan. Cancer Epidemiol Biomarkers Prev 2012;21:1986-92.

21. Branstetter SA, Mercincavage M, Muscat JE. Time to first cigarette predicts 4-(methylnitrosamino)-1-(3-pyridyl)-1-butanol (NNAL) in adolescent regular and intermittent smokers, National Health and Nutrition and Examination Survey (NHANES) 2007-10. Addiction 2014;109: 1005-12.

22. Grainge MJ, Shahab L, Hammond D, O'Connor RJ, McNeill A. First cigarette on waking and time of day as predictors of puffing behaviour in UK adult smokers. Drug Alcohol Depend 2009;101:191-5.

23. Gozukara MY, Borekci A, Gur M, Aksoy N, Seker T, Kaypaklı O, et al. Gamma glutamyl transferase activity is associated with both paraoxonase activity and aortic stiffness in hypertensive patients. J Clin Lab Anal 2014 Aug 17 [Epub]. http://dx.doi.org/10.1002/jcla.21785.

24. Hatsukami DK, Le CT, Zhang Y, Joseph AM, Mooney ME, Carmella SG, et al. Toxicant exposure in cigarette reducers versus light smokers. Cancer Epidemiol Biomarkers Prev 2006;15:2355-8.

25. Strasser AA, Malaiyandi V, Hoffmann E, Tyndale RF, Lerman C. An association of CYP2A6 genotype and smoking topography. Nicotine Tob Res 2007;9:511-8.

26. Kim DH, Suh YS. Smoking as a disease. Korean J Fam Med 2009;30:494502.

27. Kotchen T. Hypertensive vascular disease. In: Kasper DF, Hauser S, Longo D, Jameson J, Loscalzo J, editors. Harrison's principles of internal medicine. 19th ed. New York: McGraw-Hill; 2015. p. 1611-27.

28. Schillaci G, Bilo G, Pucci G, Laurent S, Macquin-Mavier I, Boutouyrie P, et al. Relationship between short-term blood pressure variability and large-artery stiffness in human hypertension: findings from 2 large databases. Hypertension 2012;60:369-77. 